\title{
Comparison of Risk Categorization Methods in a Multisim- ulation Framework
}

\author{
Adam Krasuski ${ }^{1, *}$ and Lukasz Kuziora ${ }^{1}$ \\ ${ }^{1}$ The Main School of Fire Service, Faculty of Fire Safety Engineering, 52/54 Słowackiego St., 01-629 \\ Warsaw, Poland
}

\begin{abstract}
In this article, we discuss various methods for risk categorization. We consider a statistical decision theory-based method, risk matrices, derivation of the risk acceptance level from fire data, and a comparative study. The values of risk used in the categorization process derive from multisimulation - a probabilistic fire risk assessment method. Following the theoretical description of the methods, a case study of a five story hotel building $20.000 \mathrm{~m}^{2}$ is elaborated and discussed as proof of concept. Based on the case study we reveal the shortcomings of the methods compared.
\end{abstract}

\section{Introduction}

In most countries, fire safety is based on the legal regulations. These regulations define prescriptively how to deal with specific problems related to safety assurance. The legal regulations are more or less regularly updated. Two main factors are triggering the changes in standards and codes. First, technological shift introducing new materials and methods into the marketplace. Second, high-consequence events that occur, revealing weaknesses in the regulations.

The propositions of the modifications are considered against a set of selected representative buildings. However, they are eventually generalized to apply to any building. Due to a variation in building design, compartmentalization, and materials used for construction and decoration, the generalization should allow for flexibility assuring desire safety level. In many cases, flexibility and safety are opposed goals challenging to be satisfied mutually. Therefore, many regulations have clauses for equivalency or alternate methods or materials. These clauses permit the use of approaches or materials not listed in the codes. However, there should be demonstrated that they provide at least an equivalent level of safety as that achieved by compliance with the code or standard. The demonstration is mostly based on the engineering calculations.

The engineering approach to fire protection design can be validated within the deterministic or probabilistic analysis. A candidate design is evaluated by applying fire engineering calculations to assess the impact of various fire scenarios on the building and its occupants. The design is considered acceptable if the calculations show that the design meets established quantitative performance criteria.

The definition of the acceptance parameters and their further validation through deterministic or hazard analysis is straightforward [1]. However, for probabilistic analysis, it is

\footnotetext{
*e-mail: akrasuski@sgsp.edu.pl
} 
somehow complicated. The deterministic analysis results in true/false easy to interpret value. Contrary, a probabilistic analysis will result in a probability distribution. The assessment of such a result requires to define the limit of acceptability.

A risk analysis is meagrely discussed, engineering approach to building design, treated as an exception in a few specialized area (e.g., nuclear or airline industry) [1,2] or loosely incorporated in validation framework $[3,4]$. However, a probabilistic evaluation of the safety level of people present in buildings in the context of fire safety design attracts currently a lot of attention.

Multiple probabilistic risk assessment methods have been developed in order to calculate the value of individual and societal risk [5-9]. However, having the value of risk, fire safety engineers finally face the problem of its evaluation. That means they have to decide whether given value of risk is acceptable or needs reduction.

There is no broadly accepted value of risk that can be treated as acceptable. Therefore, many approaches have been proposed to address this issue. The acceptable level of risk is generally related to the societal willingness to pay for safety. Therefore the number of methods to the problem in question is related to the Gross Domestic Product or Life Quality Index [10]. The level of risk that is acceptable by given society is also reflected in legal regulations related to the fire safety. Therefore, the broadly accepted method of risk evaluation is a reference to the risk level imposed by building that is compliant with fire safety codes and standards.

In this article, we compare various methods for risk categorization. The risk calculation is performed by use of multisimulation approach, that belongs to stochastic simulation methods based on Monte Carlo [11].

\section{Methods and Materials}

Multisimulation is an integrated methodology for quantitative fire risk assessment [12]. The purpose of multisimulation is the quantification of life safety level of people in buildings in the context of fire safety design.

The name multisimulation derives from the idea of performing many deterministic simulations (in the form of a stochastic process) on the number of various models. The models used in multisimulation are fire models, evacuation model, the toxic effect of smoke on human, thermal injury model, fire brigade intervention model, infrastructure reliability model, and others. In general, multisimulation is an umbrella of any model that may be used in the assessment of fire effect on human, property or environment. These models are fed with data from stochastic simulator - Monte Carlo. Then the results of consecutive simulations are summarized in the form of various distributions.

Multisimulation takes advantages from the works of Simo Hostikka on Probabilistic Fire Simulator [7] and Two Model Monte Carlo approach [13] as well as Charles Fleischmann (B-Risk) [14]. However, multisimulation expand the approach by the number of new submodels used, the scope of probabilistic modeling, as well as sampling, calculation techniques and presentation of the results.

A case study used to present the calculation is based on a medium rise office building, with five overground stories. The problem we face is changing the use of this building, from office to hotel category. After changing the category, the building under question is no longer compliant with the fire codes. The length of emergency routes is exceeded. The length required for an office building is $20 \mathrm{~m}$. However, for hotel category, a new maximum length of $10 \mathrm{~m}$ is demanded. Figure 1 depicts the escape routes where these requirements are not met. 


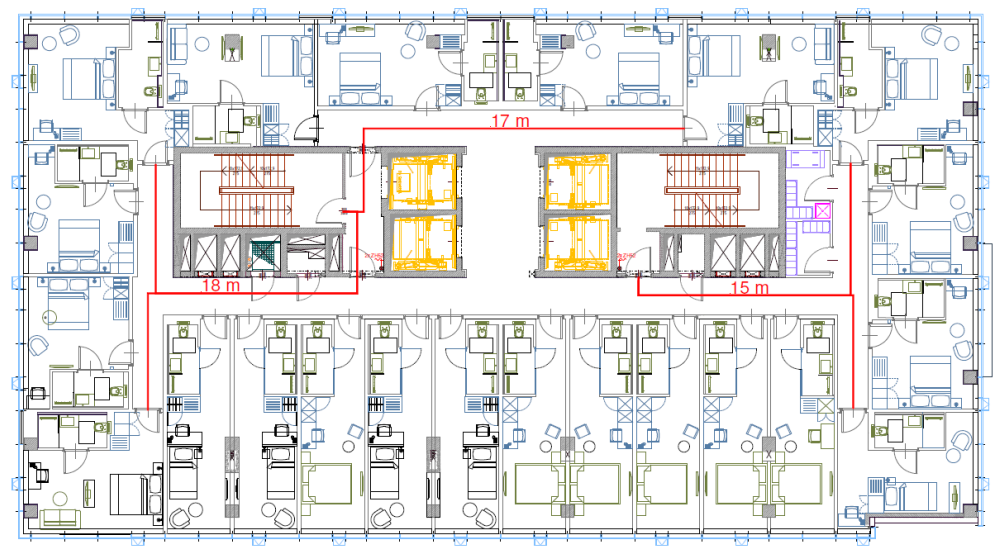

Figure 1. The designed space arrangement after the category change

We are looking for a solution that satisfy the safety level for new building category. We propose the following alternatives in order to satisfy safety criteria:

A1 - direct adjustment by changing the interior design. The proposed variant assumes adjusting the room arrangement directly to meet the requirements of the regulations. This is achieved by dividing each floor into rooms in such a way that the length of the emergency route in any evacuation direction does not exceed $10 \mathrm{~m}$. With the arrangement method suggested by this variant, the number of rooms is reduced by 7 for each floor.

A2 - direct adjustment through the use of a sprinkler system and smoke ventilation. The proposed variant assumes adjusting the room arrangement directly to meet the requirements of the regulations. Acceptable emergency route lengths without changing the interior arrangement can be achieved using a sprinkler system, to allow the route length to be extended by $50 \%$, and a smoke exhaust ventilation system, to allow the evacuation route length to be extended by a further $50 \%$. This gives a total of $20 \mathrm{~m}$.

A3 - alternative solutions with smoke ventilation and emergency lighting. The scope of this option involves an alternative solution. The safety concept here is the use of smoke ventilation, which will extend the length of the emergency routes by $50 \%$, i.e., to $15 \mathrm{~m}$, and of additionally illuminated emergency exit signs with a light intensity of 5 lux.

A4 - alternative solution with sprinkler system and emergency lighting. The safety concept here is the use of a sprinkler system, which extends the length of the emergency route by $50 \%$, i.e., to $15 \mathrm{~m}$, and of additionally illuminated evacuation signs with a light intensity of 5 lux.

A5 - alternative solution with illuminated emergency exit signs, training procedures and audits. In terms of technical solutions, the following elements are used: a single-stage alarm system, illuminated emergency exit signs and, additionally, the separation of rooms with EI60 partitions, including the use of fire-resistant installation culverts. In the scope of procedural solutions, the following elements are used: appropriate training for personnel, fire protection audits and the appointment of people responsible for evacuation from a given floor.

A6 - illuminated escape signs only. In order to compensate for the exceeded emergency route length, we apply only illuminated emergency exit signs.

In order to compare the risk for given alternatives, an average of about 3000 computer simulations were performed for each of the alternatives. The analysis included various fire scenarios, taking into account the different materials subject to combustion, the speed of de- 
velopment and the strength of the fire, the location of the fire and the reaction of the people and safety systems. Calculations were performed on Aamks ${ }^{1}$ software that implements the idea of multisimulation. The risk related to the consecutive solutions and costs of the investment are presented in Table 1. The costs of investment for given building are based on the calculations specific to building in question.

Table 1. A summary of risk values and the costs of investment for the presented alternatives. R1 - risk that evacuees will inhale a negligible amount of fire gases; R2 - risk that evacuees will inhale an amount of fire gases resulting in minor injury. R3 - risk that evacuees will inhale an amount of fire gases resulting in severe injury. R4 - risk that evacuees will inhale an amount of fire gases resulting in death. I - costs of investment.

\begin{tabular}{|l|c|c|c|c|c|c|}
\hline R/I & $\mathrm{A} 1$ & $\mathrm{~A} 2$ & $\mathrm{~A} 3$ & $\mathrm{~A} 4$ & $\mathrm{~A} 5$ & $\mathrm{~A} 6$ \\
\hline $\mathrm{R} 1$ & $2.28 \times 10^{-6}$ & 0 & $2.38 \times 10^{-6}$ & $1.80 \times 10^{-5}$ & 0 & 0 \\
\hline R2 & $1.62 \times 10^{-5}$ & $1.47 \times 10^{-5}$ & $3.73 \times 10^{-5}$ & $7.69 \times 10^{-5}$ & $1.84 \times 10^{-5}$ & $3.65 \times 10^{-5}$ \\
\hline R3 & $1.40 \times 10^{-5}$ & $1.82 \times 10^{-6}$ & $4.59 \times 10^{-6}$ & $3.40 \times 10^{-5}$ & $1.16 \times 10^{-5}$ & $2.31 \times 10^{-5}$ \\
\hline R4 & $1.26 \times 10^{-4}$ & $1.82 \times 10^{-6}$ & $1.16 \times 10^{-5}$ & $1.36 \times 10^{-5}$ & $1.21 \times 10^{-4}$ & $1.42 \times 10^{-4}$ \\
\hline $\mathrm{I}$ & $\$ 2,000,000$ & $\$ 563,000$ & $\$ 78,000$ & $\$ 510,000$ & $\$ 12,000$ & $\$ 5,000$ \\
\hline
\end{tabular}

\section{Results}

The risk calculated in Aamks software constitutes the input for risk categorization methods. In this study we compare: statistical decision theory, SFPE Risk matrix, derivation of societal acceptable risk level, and comparative analysis methods.

\subsection{Statistical Decision Theory}

According the statistical decision theory, the rational decision is that minimizing the loss function $L(\theta, a)$. The loss function is a real valued non-negative function, defined for all points of states of the nature $\theta \in \Theta$ and for all alternatives $a \in \mathrm{A}$, which expresses the relative importance of the error committed by accepting $a$ when $\theta$ is true [15]. An alternative $a^{*}$ is Bayes if:

$$
a^{*}=\operatorname{argmin} \int_{\Theta} L(\theta, a) \pi(\theta) d \theta
$$

According to the definition, we need to calculate the loss function for all of the alternatives and state of nature, and then choose an alternative, where the value of loss function is minimized. However, the costs of investment are in monetary value and risk is expressed in a probability of a fatality in case of fire. Therefore, we need to transform loss in human life into monetary value. The assessment of the monetary value of life is disputable; however various domain perform these calculations. For the purpose of this article, we assume a monetary value of life as $\$ 9,000,000$ [16-18]. Moreover, from FN curves obtained from multisimulation, we assume that average ten people may be affected in the case of fire.

According to the data presented in Table 2 Bayes alternative is A3, because it is described by the smallest value of the expected loss.

\footnotetext{
${ }^{1}$ gihub.com/aamks
} 
Table 2. A summary of the expected loss for the presented solutions. The estimation is for 100 years investment.

\begin{tabular}{lc} 
Alternative & Loss function $[\$]$ \\
A1 & $1.26 \times 10^{-4} \cdot\left(9 \times 10^{8}+2.00 \times 10^{6}\right)+\left(1-1.26 \times 10^{-4}\right) \cdot 2.00 \times 10^{6}=2.11 \times 10^{6}$ \\
A2 & $1.82 \times 10^{-6} \cdot\left(9 \times 10^{8}+5.63 \times 10^{5}\right)+\left(1-1.82 \times 10^{-6}\right) \cdot 5.63 \times 10^{5}=5.64 \times 10^{5}$ \\
A3 & $1.36 \times 10^{-5} \cdot\left(9 \times 10^{8}+7.80 \times 10^{4}\right)+\left(1-1.36 \times 10^{-5}\right) \cdot 7.80 \times 10^{4}=9.02 \times 10^{4}$ \\
A4 & $1.16 \times 10^{-5} \cdot\left(9 \times 10^{8}+5.10 \times 10^{5}\right)+\left(1-1.16 \times 10^{-5}\right) \cdot 5.10 \times 10^{5}=5.20 \times 10^{5}$ \\
A5 & $1.21 \times 10^{-4} \cdot\left(9 \times 10^{8}+1.20 \times 10^{4}\right)+\left(1-1.21 \times 10^{-4}\right) \cdot 1.20 \times 10^{4}=1.21 \times 10^{5}$ \\
A6 & $1.42 \times 10^{-4} \cdot\left(9 \times 10^{8}+5.00 \times 10^{3}\right)+\left(1-1.42 \times 10^{-4}\right) \cdot 5.00 \times 10^{3}=1.33 \times 10^{5}$ \\
\hline
\end{tabular}

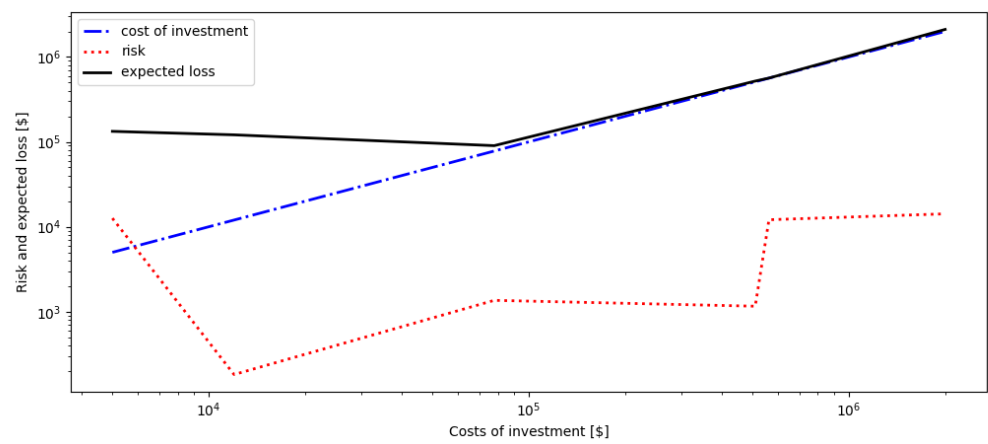

Figure 2. Visualization of risk and expected loss in a function of costs of investment. Minimal value for expected loss function is for alternative A3.

\subsection{SFPE Risk Matrix}

The SFPE Risk matrix is a proposition of Society of Fire Protection Engineers to the problem of definition of the values of acceptable risk levels [2]. The matrix consists in consequences presented in rows and probability/frequencies presented in columns. It defines the four groups of consequences: high (H) for fatality, medium (M) for heavy injury, low (L) for light injury and negligible $(\mathrm{N})$ for negligible consequences. The probability of an unwanted event is divided into four ranges: $\leq 1 \times 10^{-6} ;\left(1 \times 10^{-6}-1 \times 10^{-4}\right] ;\left(1 \times 10^{-4}-1 \times 10^{-2}\right]$; and $>1 \times 10^{-2}$. Categorization of the risk, based on the SFPE Risk matrix, involves placing the calculated risk into the matrix and reading the risk categories. Figure 3 depicts the risk categorization for the building in question. According to this matrix, alternatives A1, A5, A6 have unaccepted risk level and should be excluded from the further decision process.

\subsection{Derivation of Societal Acceptable Risk Level}

The SFPE Risk matrix is perceived as a preservative approach, which stresses safety without any cost/benefit analysis. Moreover, it mostly reflects the acceptable risk level of society of the United States. As was mentioned, the level of risk that is accepted by given society 


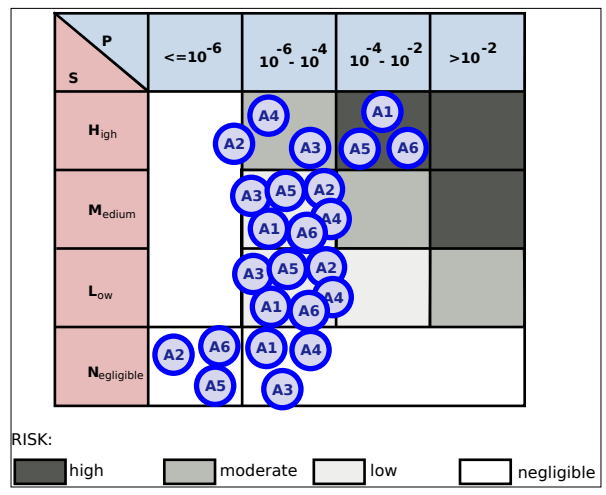

Figure 3. Risk categorization using SFPE Risk matrix.

depends mainly on the wealth of society and varies among countries. US society is rather wealthy, therefore acceptable risk level is relatively low.

In order to better address this problem, it should be necessary to apply the values of acceptable risk level, specified for a given country. One of the methods that can be used to derive acceptable risk level is its calculation from fire statistics. The method is based on a mild assumption that the standards and codes define the acceptable risk level for society and it is reflected in fire statistics.

In order to calculate acceptable risk level by the polish society we use statistics of State Fire Service of Poland from years 1993 - 2014 [19]. The area under investigation was Warsaw City and surrounding communities. The supporting domestic data was taken from the reports of Statistics Poland [20].

For the acceptable risk level of fire damage in residential buildings, we make the following calculation: Out of 30,000 fires in average per year in Poland, about 26,000 are residential fires. The average surface area of homes in Poland equals $73.8 \mathrm{~m}^{2}$. The total habitable area of Polish homes is over $1 \times 10^{9} \mathrm{~m}^{2}$. Hence the probability of a residential fire in Poland is $2.47 \times 10^{-5}$ per year per $m^{2}$.

From this data, we can calculate the probability that a home fire can threaten a person. The value of this probability equals $6.76 \times 10^{-4}$ per person per year. The average number of fire victims per year in Poland equals 500. This means that the probability that one cannot escape from a residential fire is about $1.92 \times 10^{-2}$ of the incidents. Multiplication of this value with probability to be threatened by the fire, results in acceptable risk level, that equals $1.30 \times$ $10^{-5}$. Table 3 summarizes the calculations. Table 4 presents the comparison of following alternatives with derived risk acceptable level. Only risks A2, A3 have lover risk level than those accepted by Polish society.

\subsection{Comparative study}

The alternative method - of deriving the risk level that is acceptable by given society - is a comparative study. In this study, we compare the instance of the design project that is compliant with the standards and codes and alternative propositions. The calculation of acceptable risk level by the comparative study is more direct, comparing the method based on fire statistics.

In this approach, we create a design project of the building in question, that is fully compliant with standards and codes. Then we calculate the risk for this instance. The resulted 
Table 3. The calculations of acceptable risk level based on fire statistics.

\begin{tabular}{lr} 
Number of residential fires per year: & $\begin{array}{r}N_{f}=26,000 \frac{1}{\text { year }} \\
\text { Total habitable area: }\end{array}$ \\
Habitable area per person: & $A_{h}=1,053,251,803 \mathrm{~m}^{2}$ \\
Fatality rate in fire: & $A_{p}=27.4 \mathrm{~m}^{2}$ \\
Average ignition frequency: & $R_{f}=1.92 \times 10^{-2} \frac{\text { persons }}{\text { fire }}$ \\
Probability to be threatened by home fire: & $I_{f}=\frac{N_{f}}{A_{h}}=2.5 \times 10^{-5} \frac{1}{m^{2} \text { year }}$ \\
Probability to die in home fire: & $P_{t}=6.76 \times 10^{-4}$ \\
\hline
\end{tabular}

Table 4. The comparison of the risk of consecutive alternative with the derived risk acceptance level $\mathbf{1 . 3 0} \times \mathbf{1 0}^{-5}$. The arrows up indicate that the risk is higher than acceptance level, while arrows down accordingly lower risk.

\begin{tabular}{|c|c|c|c|c|c|}
\hline A1 & A2 & A3 & A4 & A5 & A6 \\
\hline$\uparrow 1.26 \times 10^{-4}$ & $\downarrow 1.82 \times 10^{-6}$ & $\downarrow 1.16 \times 10^{-5}$ & $\uparrow 1.36 \times 10^{-5}$ & $\uparrow 1.21 \times 10^{-4}$ & $\uparrow 1.42 \times 10^{-4}$ \\
\hline
\end{tabular}

value is used as the reference value in further analysis. Then we prepare the alternative projects with various safety measures and compare the risk values of these alternatives with the reference value. Finally, we choose those project that the risk value at least equals the reference value (or is lower) and is most favorable by the investor in the face of the costs the of investment.

In the proposed alternatives, $\mathrm{A} 1$ and $\mathrm{A} 2$ are those that are fully compliant with fire codes. Within this set the risk value of alternative A1 equals $1.26 \times 10^{-4}$ and is comparatively higher than A2, which equals $1.82 \times 10^{-6}$. Since A1 and A2 alternatives are both fully compliant with fire codes, then the risk value of A1 (even that is higher) may be used as the reference value. Then the reference value $1.25 \times 10^{-4}$ will be used for further analysis.

Within the set of all the alternatives, A3-A5 have lower risk value than the reference value, and should be included for further investigation. Within this sub-set lowest cost of investment has alternative A5. Hence the alternative A5 is favored for the investor.

\section{Discussion}

We proposed six alternatives for the safety assurance in a hotel building. For each of the alternative, we calculate the risk with using multisimulation approach and Aamks software. The obtained risk values are then, the subject for comparison for methods for risk categorization. We apply the statistical decision theory based method, SFPE Risk matrix, derivation of acceptable risk level from fire statistics and comparative study.

Within this set, the statistical decision theory based method is a handy tool that allows for the comparison of various alternative taking into account also the cost of investment. The method is concentrated on minimization of expected loss. The graphical representation of the output from this method (see Fig. 2) allows for finding optimally spend money for investment in safety. The method also allows for calculating the costs of changing the alternative to less risky. The shortcomings of this method are the representation of life in monetary value, 
what is disputable. Since the method is based only on the costs of investment, it not reflects the willingness of society to pay for safety. This is also perceived as a shortcoming of this method.

The SFPE matrix is an elementary method to apply for risk categorization. However, it is perceived as a very preservative since it is based on western countries risk acceptance level. The other shortcoming of this method is lack of costs of investment in risk categorization. Hence, the alternatives that match the high risk should be averted regardless of the costs. This may cause unjustified high investment in safety measures.

The derivation of acceptable risk level from fire statistics is more fitted to the given society. However, it has the same shortcomings as SFPE matrix regarding the lack of costs of investment in the selection of safety measures.

The comparative study is a method that is very close to the building in question. The comparison of risk is based on the reference value that is calculated on the design project fully compliant with fire codes. However, due to lack of support in broader statistics, the risk level may occasionally be very low. Moreover, since there may be many project instances compliant with codes, there is a problem of selection this of critical significance.

\section{References}

[1] M.J. Hurley, E.R. Rosenbaum, Performance-based fire safety design (CRC Press, 2015)

[2] Hurley, M. J. et. al., SFPE handbook of fire protection engineering (Springer, 2015)

[3] V. Beck, Fire Saf. Sci. 5, 23 (1997)

[4] G. Baker, C. Wade, M. Spearpoint, C. Fleischmann, Proc. Eng. 62, 639 (2013)

[5] B. Karlsson, B. Tomasson, Fire Saf. Sci. 8, 901 (2005)

[6] B. Van Weyenberge, X. Deckers, R. Caspeele, B. Merci, Fire Technol. pp. 1-32 (2018)

[7] S. Hostikka, O. Keski-Rahkonen, Nucl. Eng. Des. 224, 301 (2003)

[8] S. Haouari-Harrak, P. Fromy, P. Boulet, R. Mehaddi, E. Blanchard, Fire risk assessment with a stochastic approach - Model development and application to an auditorium, in Interflam (2016)

[9] C. Wade, G. Baker, K. Frank, R. Harrison, M. Spearpoint, B-RISK 2016 user guide and technical manual. Study Report SR364, BRANZ (2016)

[10] K. Fischer, Bericht IBK 357 (2014)

[11] A.B. Owen, Monte Carlo theory, methods and examples, (Stanford, 2013),

[12] A. Krasuski, P. Kubica, M. Pecio, Ochr. Ppoz. 60 (2017)

[13] S. Hostikka, T. Korhonen, O. Keski-Rahkonen, Fire Saf. Sci. 8, 1241 (2005)

[14] C. Wade, G. Baker, K. Frank, R. Harrison, M. Spearpoint, B-RISK 2016 user guide and technical manual (2016), study report SR364 [2016]

[15] G. Parmigiani, L. Inoue, Decision theory: principles and approaches, Vol. 812 (John Wiley \& Sons, 2009)

[16] B. Appelbaum, New York Times (2011)

[17] K. Thomson, C. Monje, US Department of Transportation: Office of the Secretary of Transportation, June 17 (2015)

[18] R.D. Guidance (2007)

[19] W. Leśniakiewicz, Zasady ewidencjonowania zdarzeń w systemie wspomagania decyzji państwowej straży pożarnej (2014), komenda Główna Państwowej Straży Pożarnej

[20] I. Adamczyk, E. Knyszewska, Gospodarka mieszkaniowa w 2016 r (2017), Główny Urząd Statystyczny 